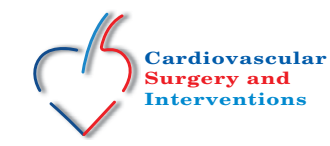

\title{
Aortoenteric fistulas: A case report and current status
}

\author{
Ahmet Coşkun Özdemir ${ }^{1}$ (D) Hüseyin Gemalmaz² (D), Fatih Yllmaz ${ }^{3}$ (D) \\ 'Department of Cardiovascular Surgery, Karadeniz Technical University School of Medicine, Trabzon, Turkey \\ ${ }^{2}$ Department of Cardiovascular Surgery, Bahçelievler Memorial Hospital, Istanbul, Turkey \\ ${ }^{3}$ Department of Cardiovascular Surgery, Batıkent Medical Park Hospital, Ankara, Turkey
}

Received: September 07, 2020 Accepted: October 22, 2020 Published online: November 13, 2020

\begin{abstract}
Aortoenteric fistulas are rare, but mostly fatal if left untreated. Diagnosis and treatment are challenging. Aortoenteric fistulas can occur either as a complication of aortic aneurysm or, more commonly, secondary to previous aortic reconstructive surgery. Conventional treatment options are graft excision and extra-anatomic bypass or in situ graft replacement. This treatment is associated with high morbidity and mortality rates. Endovascular repair is an emerging therapeutic option. In this article, we describe a case of aortoenteric fistula which was not secondary to a previous reconstructive aortic surgery and discuss the diagnosis and treatment of these fistulas in the light of a comprehensive literature review.
\end{abstract}

Keywords: Aortoenteric fistula, axillobifemoral bypass graft enteric fistula, graft infection, in situ graft.

Aortoentric fistulas (AEFs) are seen rarely, but if left untreated, death is almost inevitable. They usually occur between an aneurysmal segment of the aorta and a neighboring gastrointestinal (GI) structure or between an aortic graft and the intestine in patients having a prior aortoiliac reconstructive surgery. ${ }^{[1]}$ The main symptom in the majority of patients is GI bleeding. Currently, the most commonly used diagnostic tool is computed tomography (CT). The diagnosis can be easily overlooked, as clinical symptoms may vary, radiological findings are generally non-specific, and diagnostic tools have a low sensitivity. A patient who has an aortic aneurysm or a prior aortic surgery and suffers from GI bleeding must be definitely assessed for AEFs. The AEFs are commonly treated with an extra-anatomic bypass (EAB) or in situ bypass (ISB), while endovascular treatment has also become an increasing option in recent years. In this article, we present a secondary AEF case developed four years after gynecological surgery with no aneurysm in the aorta or its branches and no aortic prosthesis or graft. We also discuss the diagnosis and treatment of AEFs in the light of a comprehensive literature review.

\section{CASE REPORT}

A 56-year-old female patient presented to the emergency department of our hospital complaining about poor general condition and melena. On her physical examination, the blood pressure was $85 / 50 \mathrm{mmHg}$ and pulse $115 / \mathrm{min}$. No abdominal pain or tenderness was noted. Hemoglobin level was $8.4 \mathrm{mg} / \mathrm{dL}$ in the initial complete blood count analysis and $8 \mathrm{mg} / \mathrm{dL}$ in the next control carried out $1 \mathrm{~h}$ later. Her medical history revealed a history of total abdominal hysterectomy + bilateral salpingo-oophorectomy four years ago. Abdominal ultrasound did not reveal any signs compatible with her complaints and there was no need for emergency colonoscopy and sigmoidoscopy. On abdominal CT, free air was detected in the paraaortic area adjacent to the posterior third part of the duodenum and reduction in the fat plane between the third part of the duodenum and the aorta. Since hyperdense areas suggesting hematoma were also found in the second part of the duodenum, and the patient was assessed for an AEF. A written informed consent was obtained from the patient and she was urgently operated.

Corresponding author: Ahmet Coşkun Özdemir, MD. Karadeniz Teknik Üniversitesi Tıp Fakültesi Kalp ve Damar Cerrahisi Anabilim Dalı, 61080 Ortahisar, Trabzon, Turkey.

Tel: +90 462 - 3775055 e-mail: drcozdemir@yahoo.com

\section{Citation:}

Özdemir AC, Gemalmaz H, Yllmaz F. Aortoenteric fistulas: A case report and current status. Cardiovasc Surg Int 2020;7(3):193-198. 
During the operation, retroperitoneum was opened previously, and an AEF was observed to develop in this region between the third part of the duodenum and the left proximal end of the iliac artery. The duodenum was detached and was primarily repaired. The iliac artery was fixed at the proximal and distal parts of the fistula. Then, a suprapubic graft was placed between the right and left femoral artery. The operation was completed in this way; however, since the intestinal content was running from the drains on postoperative Day 4, she was reoperated. The patient was administered intestinal resection and bypass and no other problems occurred during follow-up. When the gynecology department was consulted, the patient was learnt to previously undergo a retroperitoneal lymph node dissection in this region during the initial gynecological surgery. The patient is still alive without any complications at 15 months of her follow-up.

\section{Description}

$\mathrm{An} \mathrm{AEF}$ is an open connection developed between the aorta or its major branches and GI tract. It can develop without any prior aortic intervention, which is called primary AEF (PAEFs), and the first case was published by Salmon in $1843 .{ }^{[2]}$ Its prevalence is between 0.04 and $0.07 \%$ in the general population. ${ }^{[3]}$ The PAEFs usually occur between an aneurysmal aortic segment and an adjacent GI structure (73 to 88\%); however, they can also develop due to tumors, infections, radiotherapy, peptic ulcers, inflammatory intestinal diseases, and foreign objects without the presence of an aneurysm. ${ }^{[4]}$ A fistula between a vascular prosthesis placed during an aortic surgery and any part of the GI tract is called a secondary AEF (SAEF), which was first described by Brock in 1953. ${ }^{[5]}$ These are more common compared to PAEFs with a reported incidence between 1.6 and $2 \%$ after an aortoiliac surgery. ${ }^{[6,7]}$ Its incidence may increase up to $14 \%$ after an emergency rupture aneurysm surgery where bacterial contamination and iatrogenic intestinal injuries are more likely. ${ }^{[8]}$

The SAEFs usually develop due to continuous physical stimulation or infection occurring during an index aortoiliac reconstructive surgery. However, they can also occur in rare cases due to interventions to the aorta or its major branches during surgical procedures performed for other purposes. ${ }^{[9]}$ Another condition which extremely resembles SAEFs, is aortoenteric erosion (AEE). In AEE, the vascular prosthesis leads to erosion on the outer layers of a neighboring GI structure, causing intestinal mucosa to surface. There is a contact between the intestinal mucosa and the prosthetic graft body, but no fistulization. The graft wall is strong enough to prevent any blood passage from the vascular compartment to the GI lumen. The bleeding in AEE usually originates from the intestinal mucosa. In true SAEFs, however, the contact is between the intestine and the anastomotic margin of the graft, which is usually the proximal anastomotic line. ${ }^{[1]}$ The distinction between these two entities is nothing, but a matter of definition. Since the treatment and clinical course of both conditions are almost the same, publications usually address into these two conditions under the same topic. Although the mechanism leading to AEFs has not been elucidated fully, it is thought that the constant pulsatile trauma exerted by the aneurysmal sac to the adjacent structure leads in time to erosion and fistulization in PAEFs. For SAEFs, the agents penetrating the locus from enteric structures that erode through chronic pulsatile stimulus of the prosthetic object and its anastomosed lines or the infection caused by the graft contaminated during the initial surgical intervention are thought to play a key role in the development of a fistula. The inflammation resulting from infection leads to pseudoaneurysms in the anastomotic region, which is the most sensitive part of the vascular structure, followed by formation of a fistula. ${ }^{[3,9-12]}$ The iatrogenic traumas occurring in the intestinal structures during surgery should be also considered in the etiology.

Although AEFs can occur anywhere along the GI tract, more than half of them are seen in the duodenum. The most commonly involved section of the duodenum is its third part. ${ }^{[13]}$ This retroperitoneal part of the duodenum has a fixed location between the Treitz ligament, aorta, and superior mesenteric artery. The closeness of this transverse part of the duodenum to the aorta and proximal anastomosis of the graft makes the duodenum more susceptible to AEF development.

\section{Signs and symptoms}

Due to the relationship of AEFs with vascular and intestinal lumens, the most expected symptom in these patients is GI bleeding. A large majority of the patients present with hematemesis (54\%) and melena (41\%), while other common symptoms are abdominal pain (21\%), sepsis (12\%), and fever (11\%). ${ }^{[13,14]}$ The triad of GI bleeding, abdominal pain, 
and pulsatile mass in the abdomen, which was defined by Cooper ${ }^{[15]}$ approximately 200 years ago and agreed to be pathognomonic for PAEF, is seen only in $11 \%$ of the patients. ${ }^{[13]}$ Patients with PAEFs and SAEFs usually have the same clinical signs. One of the major characteristics of these patients is that they usually have a herald bleed before the massive GI bleeding occurs. This herald bleed which happens hours or days before the life-threatening bleeding is mostly self-limiting. ${ }^{[16-18]}$ This limitation is thought to be associated with the thrombus forming in the relatively small fistula in the patient who becomes hypotensive due to bleeding. In the following days and hours, this thrombus leaves its place and abundant bleeding starts to take place. Therefore, it is important to avoid aggressive fluid replacement at the time of hospital admission and to keep the systolic blood pressure in the 70 to $100 \mathrm{mmHg}$ interval. In addition, signs of sepsis such as fever, leukocytosis, weakness, and bacteremia are seen in $41 \%$, shock in $46 \%$, and pain in $22 \%$ of the patients. ${ }^{[19]}$

\section{Diagnosis}

The most important step in diagnosing AEFs is to keep the suspicion of an AEF in mind. Since AEFs are less common among the causes of GI bleeding, clinicians may not be knowledgeable enough on this pathology, and the signs and symptoms quite differ from case to case, and the sensitivity of imaging methods are relatively low, and the diagnosis is often missed. Therefore, if a patient who presented with complaint of GI bleeding has an aortic aneurysm or a previous aortoiliac surgery, he/she should be considered to have an AEF, until otherwise evidenced. ${ }^{[20]}$ Even if no active bleeding is found in physical examination, such patients should be closely observed and their vital signs continuously monitored, as they usually experience a herald bleed before the onset of their abundant bleeding. ${ }^{[16,17]}$ Currently, the most commonly used imaging method is CT. ${ }^{[21,22]} \mathrm{As}$ it is readily available, has relatively easy application and short scan time, and gives a lot of information for the differential diagnosis, CT is the most suitable diagnostic tool for the diagnosis of AEFs. The most important $\mathrm{CT}$ finding in AEFs is the gas detected in the aorta or in adjacent regions. ${ }^{[23]}$ However, the presence of gas is not specific to AEF alone. It is normal to find free gas in this region within the first month following an aortoiliac surgery. Gas in this region can be also detected in graft infections without the presence of a fistula. However, any soft tissue, gas or fluid to be found around the graft after Week 7 should be considered as a perigraft infection. ${ }^{[24]}$ The most specific indication is the contrast penetration from the aorta into the intestinal lumen, although this can be detected rarely. ${ }^{[25,26]}$ Penetration of free contrast from the aorta to the surroundings of the graft is again a specific finding; however, this is also encountered quite rarely. Non-specific signs much more commonly found than the aforementioned findings are more useful in making the diagnosis of an AEF. The most frequent signs indicating an AEF include reduced periaortic fat plane, focal thickening, and shrinkage in the neighboring intestinal wall, periaortic free fluid, free gas around the aorta, and pseudoaneurysm at the anastomotic margin.

Although the diagnostic value of gastroduodenoscopy varies in different publications, it can diagnose 25 to $50 \%$ of all AEFs. ${ }^{[27]}$ A large majority of AEFs are seen in the third and fourth parts of the duodenum, which makes it technically difficult to advance the endoscope to this region and requires synchronization between operator and patient. Nevertheless, gastroduodenoscopy is quite helpful in differentiating from other causes of GI bleeding. ${ }^{[27]}$ It gives fairly specific results in terms of scintigraphy and 18F-fludeoxyglucose (FDG) positron emission tomography (PET)/CT AEF. However, it is not much practical, since the patient must be in a stable position during the scan. Due to its less availability and longer scan time, magnetic resonance imaging (MRI) is not a highly preferred imaging method in AEFs, yet. Although not primarily a diagnostic tool for AEFs, conventional angiography can be used in patients who are eligible for transcatheter and endovascular interventions.

\section{Treatment}

Once diagnosed with an AEF, the patient should be started an empirical antibiotherapy without any delay. Microorganisms of different species are isolated in PAEFs. ${ }^{[3,13,27]}$ One of the most frequently isolated microorganisms is Candida ${ }^{[19]}$ As for bacteria, the most commonly isolated species are Escherichia coli, E. faecalis, Salmonella, Mycobacterium tuberculosis, Clostridium septicum, Lactobacillus, and Klebsiella. ${ }^{[28]}$ However, very few studies provide data on the culprit microorganism. Although studies on SAEFs have reported isolation of many different microorganisms, most of the cases involve Staphylococcus, Streptococcus spp. and Escherichi coli. ${ }^{[28]}$ Apart from these, Pseudomonas aeruginosa, 
Enterococcus spp., Veilonella spp., Peptostreptococcus spp., E. Coli, and Staphylococcus aureus have been identified in the mixed flora. ${ }^{[28]}$ Patients diagnosed with an AEF should be immediately started antimicrobial therapy in the postoperative period. The treatment should involve broad-spectrum antibiotics and antifungals covering Gram-positive, Gram-negative, and anaerobic pathogens, as well as Candida.

Patients in whom antibiotherapy is arranged should be made ready for a surgical intervention without losing time. Even if they are hemodynamically stable at the time of admission, it should be kept in mind that these patients may have abundant bleeding at any time. The liquid and blood needs of patients who are unstable or in shock should be met immediately. Afterwards, an intervention method suitable for the patient should be selected. Open surgery is a widely used and recommended treatment; however, there are ongoing works on endovascular intervention which has become increasingly popular recently.

\section{ISB versus $\mathrm{EAB}$}

The AEFs are conditions which result in death, if left untreated. Since it was first defined, AEFs have been evidenced to require surgery for treatment. The main goal of open surgery is to ascertain the diagnosis, stop bleeding, remove the infected graft, resect the infected tissues as broadly as possible, repair intestinal defect, and allow the blood flow to the distal vascular bed through a vascular prosthesis. Therefore, the EAB method has been used for the treatment of AEFs since early periods, in which the vascular prosthesis is placed away from the infected region. This approach has been agreed to be the gold standard for a long time, but it is not possible to advocate that the results are at a desired level. Several studies have reported mortality rates between 25 and $90 \%$ for $\mathrm{EAB}$, major amputation rates between 5 and $25 \%$, and aortic stump rupture rates between 10 and 50\%. ${ }^{[9]}$ Since the prolonged surgical time of $\mathrm{EAB}$ causes a serious stress in patients with an already poor general condition, the idea of a staged surgery has emerged. In patients with a stable condition, first a lower extremity blooding is achieved through EAB and, in the following days, AEF repair and graft excision are performed. This approach aims at reducing mortality. In a study including patients with aortic graft infection, postoperative mortality was found to decrease to $11 \% .^{[29]}$ Many centers have attempted ISB using an infection-resistant graft after removing the infected graft for having a low long-term graft patency, lacking the desired low reinfection rates, and having the risk of aortic stump blow-out. The Texas Houston University has started using ISB for treating AEFs and many researchers have utilized ISB technique using a variety of conduits. ${ }^{[30]}$ In general, prosthetic grafts, cryopreserved grafts, and autologous venous grafts are used for ISB.

Prosthetic grafts have become more favorable over time owing to their low cost and easy availability in various sizes, even in emergency cases. Those prosthetic grafts soaked with rifampin or amikacin or coated with silver to increase their resistance to infections are more preferable. However, there are controversial results with antibiotic-soaked grafts. ${ }^{[31]}$ Grafts soaked with rifampin yield the best outcomes in terms of amputation, conduit failure, and early mortality, although they have the highest reinfection rate. ${ }^{[31]}$ In addition, clinical studies have shown that these grafts are ineffective against methicillin-resistant bacteria such as Staphylococcus aureus and Escherichia coli. ${ }^{[32]}$ Owing to their silver ion contents, silver-coated grafts are believed to show antimicrobial effects by inhibiting deoxyribonucleic acid replication and protein transcription of messenger ribonucleic acid inside bacterial cells. Although silver-coated grafts have been shown to fail in preventing infections in the in vitro setting, some authors have reported promising results. ${ }^{[33,34]}$ Another disadvantage of the prosthetic grafts is their high graft failure and occlusion rates. ${ }^{[35]}$

Another graft used for ISB is the autologous saphenous graft. Also known as the neoaortoiliac surgical reconstruction, this method aims at restructuring the superficial femoral veins of the lower extremities to make them resistant to aortoiliac system infections. Kakkos et al. ${ }^{[36]}$ found in their study that ISB procedures where lower extremity femoral veins were used had lower mortality rates than the procedures using other grafts. The most favorable outcomes regarding the reinfection rate were also found to be associated with autologous vein grafts. ${ }^{[34]}$ Extremity complications such as edema and compartment syndrome associated with the use of lower extremity deep veins were found within acceptable limits, while only $2 \%$ of patients had fasciotomy-requiring edema and permanent leg edema. ${ }^{[37]}$ Since removal of femoral veins takes a long time and prolongs the duration of surgery, it should not be used in patients whose condition is critical, nor should it be used in those having a history of prior deep vein thrombosis. ${ }^{[38]}$ Although many publications report favorable outcomes 
with autologous vein grafts, in their 50-case series where they used femoral vein in 34 cases, Chopra et al. ${ }^{[39]}$ reported that the 30-day and 60-day mortality rates were $25 \%$ and $48 \%$, respectively.

The results of intestinal repair are independent risk factors affecting survival. Contrary to vascular approach, there is a consensus on intestinal repair. Minor intestinal defects can be repaired outright. In larger defects, however, complex surgeries should not be avoided in fear of leakage and reinfection. ${ }^{[40]}$ Since mortality from reinfection is $100 \%,{ }^{[19]}$ it is of vital importance to repair any intestinal leakage most effectively during the first session. Emergence of intestinal complications shows a homogeneous distribution within the first 60 days with an apparent decline, thereafter. Thus, caution should be exercised during the first 60 days for early mortality in AEF cases. ${ }^{[38]}$

\section{Endovascular repair}

In recent years, many studies have been published regarding the outcomes of endovascular intervention in AEFs. ${ }^{[36,41]}$ This approach has been used more frequently in patients who are ineligible for open surgery due to anatomic inconvenience or poor general condition. This method allows a much less invasive approach to closure of the fistula and prevention of bleeding. However, contrary to open surgery, it makes no contribution to the treatment of infection. Therefore, a serious risk of infection continues for the newly placed endovascular prosthesis. Review of the literature on EVAR results reveals a significant superiority to open surgery in terms of early mortality, but such a superiority disappears in the follow-up period. ${ }^{[36]}$ As endovascular treatment does not involve intestinal repair, it should not be considered as a destination treatment. In a 13-month follow-up study, Antoniau et al. ${ }^{[42]}$ reported reinfection and bleeding in $44 \%$ of the patients who were administered EVAR for AEFs. In ineligible patients, therefore, EVAR should be considered as a bridging treatment, until the patient becomes ready for open surgery, which should be administered as soon as the patient becomes eligible for it. However, used as the first-line treatment, EVAR may render in situ repair more complicated. Moreover, since the fistula originates mostly from proximal anastomosis, insertion of an endograft may pose a risk for the perfusion of renal arteries.

In conclusion, an $\mathrm{AEF}$ is a complication resulting in death, if left unrepaired. It should be kept in mind that patients who present in a stable condition may be lost due to abundant bleeding at any time; thus, a surgical intervention should be performed as soon as possible. The AEB, which has been agreed to be the gold standard in the treatment of AEFs for a long time, is now being replaced by ISB thanks to its superior results in the recent publications. Of note, no consensus has been reached yet for the grafts to be used for ISB, and none of the currently used grafts has produced a desirable outcome. Endovascular interventions which have become increasingly popular in recent years should be only used for bridging to open surgery. Performing an intestinal repair in a safe way is of vital importance. Successfully treated patients should be very closely monitored for the first 60 days for possible reinfection and bleeding.

\section{Declaration of conflicting interests}

The authors declared no conflicts of interest with respect to the authorship and/or publication of this article.

\section{Funding}

The authors received no financial support for the research and/or authorship of this article.

\section{REFERENCES}

1. Chung J. Management of aortoenteric fistula. Adv Surg 2018;52:155-77.

2. Salmon M. Aneurysme de l'aorte ventral:mort par rupture de la poche arterielle dans le duodenum. Bull Soc Anat 1843;18:283.

3. Voorhoeve R, Moll FL, de Letter JA, Bast TJ, Wester JP, Slee $\mathrm{PH}$. Primary aortoenteric fistula: report of eight new cases and review of the literature. Ann Vasc Surg 1996;10:40-8.

4. Xiromeritis K, Dalainas I, Stamatakos M, Filis K. Aortoenteric fistulae: present-day management. Int Surg 2011;96:266-73.

5. Brock RC. Aortic homografting; a report of six successful cases. Guys Hosp Rep 1953;102:204-28.

6. Wilson WR, Bower TC, Creager MA, Amin-Hanjani S, O'Gara PT, Lockhart PB, et al. Vascular graft infections, mycotic aneurysms, and endovascular infections: A scientific statement from the american heart association. Circulation 2016;134:e412-e60.

7. Chenu C, Marcheix B, Barcelo C, Rousseau H. Aorto-enteric fistula after endovascular abdominal aortic aneurysm repair: case report and review. Eur J Vasc Endovasc Surg 2009;37:401-6.

8. Tagowski M, Vieweg $\mathrm{H}$, Wissgott $\mathrm{C}$, Andresen $\mathrm{R}$. Aortoenteric fistula as a complication of open reconstruction and endovascular repair of abdominal aorta. Radiol Res Pract 2014;2014:383159.

9. Keunen B, Houthoofd S, Daenens K, Hendriks J, Fourneau I. A case of primary aortoenteric fistula: Review of therapeutic challenges. Ann Vasc Surg 2016;33:230.e5-230.e13.

10. Hagspiel KD, Turba UC, Bozlar U, Harthun NL, Cherry KJ, Ahmed H, et al. Diagnosis of aortoenteric fistulas with CT angiography. J Vasc Interv Radiol 2007;18:497-504. 
11. Hansen BA, Amundsen S, Reikvam H, Wendelbo $\varnothing$, Pedersen G. Non-curative surgery for aortoenteric fistula. J Surg Case Rep 2017;2017:rjx153.

12. Zaki M, Tawfick W, Alawy M, ElKassaby M, Hynes N, Sultan S. Secondary aortoduodenal fistula following endovascular repair of inflammatory abdominal aortic aneurysm due to Streptococcus anginosus infection: A case report and literature review. Int J Surg Case Rep 2014;5:710-3.

13. Saers SJ, Scheltinga MR. Primary aortoenteric fistula. Br J Surg 2005;92:143-52.

14. Bergqvist D, Björck M. Secondary arterioenteric fistulation - A systematic literature analysis. Eur J Vasc Endovasc Surg 2009;37:31-42.

15 Cooper A, editor. Lectures on principles and practice of surgery with additional notes and cases by Tyrell. 5th ed. Philadelphia: Haswell; 1839.

16. Pipinos II, Carr JA, Haithcock BE, Anagnostopoulos PV, Dossa CD, Reddy DJ. Secondary aortoenteric fistula. Ann Vasc Surg 2000;14:688-96.

17. Sierra J, Kalangos A, Faidutti B, Christenson JT. Aorto-enteric fistula is a serious complication to aortic surgery. Modern trends in diagnosis and therapy. Cardiovasc Surg 2003;11:185-8.

18. Armstrong PA, Back MR, Wilson JS, Shames ML, Johnson BL, Bandyk DF. Improved outcomes in the recent management of secondary aortoenteric fistula. J Vasc Surg 2005;42:660-6.

19. Batt M, Jean-Baptiste E, O'Connor S, Saint-Lebes B, Feugier P, Patra P, et al. Early and late results of contemporary management of 37 secondary aortoenteric fistulae. Eur J Vasc Endovasc Surg 2011;41:748-57.

20. Temizkan V, Uğur M, Alp İ, Uçak A, Yılmaz AT. Seconder aortoenteric fistula. Turk Gogus Kalp Dama 2013;21:1150-1.

21. Hughes FM, Kavanagh D, Barry M, Owens A, MacErlaine DP, Malone DE. Aortoenteric fistula: a diagnostic dilemma. Abdom Imaging 2007;32:398-402.

22. Perks FJ, Gillespie I, Patel D. Multidetector computed tomography imaging of aortoenteric fistula. J Comput Assist Tomogr 2004;28:343-7.

23. Raman SP, Kamaya A, Federle M, Fishman EK. Aortoenteric fistulas: spectrum of CT findings. Abdom Imaging 2013;38:367-75.

24. Qvarfordt PG, Reilly LM, Mark AS, Goldstone J, Wall SD, Ehrenfeld WK, et al. Computerized tomographic assessment of graft incorporation after aortic reconstruction. Am J Surg 1985;150:227-31.

25. Hagspiel KD, Turba UC, Bozlar U, Harthun NL, Cherry KJ, Ahmed H, et al. Diagnosis of aortoenteric fistulas with CT angiography. J Vasc Interv Radiol 2007;18:497-504.

26. Peirce RM, Jenkins RH, Maceneaney P. Paraprosthetic extravasation of enteric contrast: a rare and direct sign of secondary aortoenteric fistula. AJR Am J Roentgenol 2005;184(3 Suppl):S73-4.

27. Ranasinghe W, Loa J, Allaf N, Lewis K, Sebastian MG. Primary aortoenteric fistulae: the challenges in diagnosis and review of treatment. Ann Vasc Surg 2011;25:386.e1-5.

28. Gnus J, Ferenc S, Kościelna M, Paprocka-Borowicz M, Dawidczyk P, Dziewiszek M, et al. Secondary aortoenteric fistula after abdominal aortic graft implementation in our own material. Adv Clin Exp Med 2016;25:1265-71.

29. Seeger JM, Pretus HA, Welborn MB, Ozaki CK, Flynn TC, Huber TS. Long-term outcome after treatment of aortic graft infection with staged extra-anatomic bypass grafting and aortic graft removal. J Vasc Surg 2000;32:451-9.

30. Walker WE, Cooley DA, Duncan JM, Hallman GL Jr, Ott DA, Reul GJ. The management of aortoduodenal fistula by in situ replacement of the infected abdominal aortic graft. Ann Surg 1987;205:727-32.

31. Bandyk DF, Novotney ML, Johnson BL, Back MR, Roth SR. Use of rifampin-soaked gelatin-sealed polyester grafts for in situ treatment of primary aortic and vascular prosthetic infections. J Surg Res 2001;95:44-9.

32. Koshiko S, Sasajima T, Muraki S, Azuma N, Yamazaki K, Chiba $\mathrm{K}$, et al. Limitations in the use of rifampicin-gelatin grafts against virulent organisms. J Vasc Surg 2002;35:779-85.

33. Bíró G, Szabó G, Fehérvári M, Münch Z, Szeberin Z, Acsády G. Late outcome following open surgical management of secondary aortoenteric fistula. Langenbecks Arch Surg 2011;396:1221-9.

34. O'Connor S, Andrew P, Batt M, Becquemin JP. A systematic review and meta-analysis of treatments for aortic graft infection. J Vasc Surg 2006;44:38-45.

35. Bisdas T, Bredt M, Pichlmaier M, Aper T, Wilhelmi M, Bisdas S, et al. Eight-year experience with cryopreserved arterial homografts for the in situ reconstruction of abdominal aortic infections. J Vasc Surg 2010;52:323-30.

36. Kakkos SK, Bicknell CD, Tsolakis IA, Bergqvist D; Hellenic Co-operative Group on Aortic Surgery. Editor's Choice - Management of Secondary Aorto-enteric and Other Abdominal Arterio-enteric Fistulas: A Review and Pooled Data Analysis. Eur J Vasc Endovasc Surg 2016;52:770-86.

37. Clagett GP, Bowers BL, Lopez-Viego MA, Rossi MB, Valentine RJ, Myers SI, et al. Creation of a neo-aortoiliac system from lower extremity deep and superficial veins. Ann Surg 1993;218:239-48.

38. Dorigo W, Pulli R, Azas L, Pratesi G, Innocenti AA, Pratesi C. Early and long-term results of conventional surgical treatment of secondary aorto-enteric fistula. Eur J Vasc Endovasc Surg 2003;26:512-8.

39. Chopra A, Cieciura L, Modrall JG, Valentine RJ, Chung J. Twenty-year experience with aorto-enteric fistula repair: Gastrointestinal complications predict mortality. J Am Coll Surg 2017;225:9-18.

40. Valentine RJ, Timaran CH, Modrall GJ, Smith ST, Arko FR, Clagett GP. Secondary aortoenteric fistulas versus paraprosthetic erosions: Is bleeding associated with a worse outcome? J Am Coll Surg 2008;207:922-7.

41. Han K, Lee DY, Kim MD, Lee S, Won JY, Kwon JH, et al. Hybrid treatment: Expanding the armamentarium for infected infrarenal abdominal aortic and iliac aneurysms. J Vasc Interv Radiol 2017;28:564-9.

42. Antoniou GA, Koutsias S, Antoniou SA, Georgiakakis A, Lazarides MK, Giannoukas AD. Outcome after endovascular stent graft repair of aortoenteric fistula: A systematic review. J Vasc Surg 2009;49:782-9. 